\title{
The Dynamics of Inflation in Ethiopia: Time Series Approach
}

\author{
Getachew Mulat Kebede \\ Lecturer, Department of Economics, Aksum university, PO box 1010, Ethiopia
}

\begin{abstract}
One of the prime objectives of governments is achieving stable macroeconomic condition. This objective requires that prices be kept to a reasonably stable level. High and persistent inflation introduces uncertainties into the economy and may lead to slowdown of economic growth by discouraging domestic as well as foreign investments. It may also cause balance of payments problems by eroding a country's competitive advantage. Moreover, because it hits the poor the most it needs to be tackled. This study aims at understanding the forces behind the current inflationary process in Ethiopia. In order to achieve the stated objective a synthesis model of monetarist and costpush inflation theories is estimated using vector autoregressive (VAR) and single equation error correction models. The estimated models enable to understand the short run and the long run inflation dynamics in Ethiopia between 1980 and 2017.The result shows that in the long run real money supply. Real GDP growth real effective exchange rate and Budget deficit have significantly affect inflation. But budget deficit and real GDP is not found the expected sign rather. The short run the change in real GDP growth and change real money supply significantly affect inflation. However the change real effective exchange rate and budget deficit are insignificant. The study suggests that adopting restrictive monetary and fiscal policy. Have essential tools to curb inflationary problem of Ethiopia.
\end{abstract}

Keywords: inflation, ECM,GDP,VAR

DOI: $10.7176 / J E S D / 11-11-01$

Publication date:June 30 th 2020

\section{CHAPTER ONE}

\subsection{Introduction}

It is widely believed that moderate and stable rate of inflation promotes output growth, ensure return to saver enhance investment and accelerate economic growth. In general, price stability is an indicator of macroeconomic stability people dislike price hikes because higher inflation rate reduce the purchasing power of their money making them unable to buy, the same quantity and quality of goods and service as before, given their income. (Kibrom, 2008).

Developing countries are characterized by low level of macroeconomic performance of high population lower per capital income or low real GDP growth, underemployment, high rate of series inflation, high debt burden, unfavorable term of trade, exchange rate depreciation and market instability, (OS.Sherivastiva, 2002), with regard to developing countries again the structuralist further identified the commonly observed basic structural bottlenecks, foreign trade bottlenecks, structural deficiencies in tax system and the budget constraints, constraints in supply of social overhead capital and skilled labor.

Ethiopia as one of the developing countries has faced series macroeconomic problems such as a low GDP Growth rate, budget deficit, detoriated balance of payment and huge debt service since 1970`s the country has also faced services macro-economic shocks such as ditorated investment market, devastating drought and wars. According to world fact book(IMF,2008)Ethiopia ranked 88in terms of GDP precipitate income measure by purchasing power party (PPP) out of 229 countries, $136^{\text {th }}$ out of 162 countries in prime lending (2006), 48 out of 126 countries in public debt (45.1\% of GDP) and 21 th out of 274 countries in labor force these figures relatively showed that Ethiopia the poorest country in the world.

Ethiopia was long known for its low inflation rate but in recent time it has been plagued by inflationary process. In light if this, an overview of the trend of inflation in Ethiopia is discussed in the three regimes that have followed since, 1963.

During the derg regime inflation grew with oscillating characteristics. The average annual inflation rate for this period was $9.8 \%$.

Inflation grew in double digit percentage point for the period between 1974/75 standing at $15 \%$ the government undertook various steps to keep inflation at manageable level. Which included price control and distribution of essential commodities by the government. These measures decreased inflation pressure from $1980 / 81$ to $1983 / 84$. But in the $1984 / 85$ period inflation crept upraising due to an agricultural supply shock and ballooned to $18.45 \%$ (kejela, 2005). Other reason for this low but volatile inflation trend were the over valued national currency and the fixed exchange rates. Fiscal and monetary policies were also ineffective because the economy was centrally planned. (Kejela 2005). Under these system price intrastate rate, level of investment money supply were set by government.

In the period of 1992/1993, Ethiopia under the rule transitional government adopted economic reform. In this reform program, the national currency was devaluated, the price control was lifted. And the economy was open 
for market for the first time. Some economists believed that these measures would further exacerbate the problem but in fact inflation declined in the period between 1992/1993 to 2001/2003. There were exceptions to this period when inflation surged in the period 1991/92 due to Ethiopia-Eritrean war reaching $18.2 \%$ and in $1993 / 94$ it reached $13.4 \%$ as a result of monetary expansion and a bad harvest. In the 1992/93-2001/02 period annual inflation rate was $3.5 \%$. the reason behind this were the economic reforms program,prodent made by the government to make targets both on level and growth rate of money supply, domestic credit and financing budget deficit.

Ethiopia again experienced inflationary pressure in 2003 due to a 3.3 decline in the GDP of the fiscal year 2003. In the period between 2003/04-2008/09 inflation average 16.06 in simpel growth rate (Kejele, 2003).

According to NBE, over the last three consecutive years 2004 to 2006 the economy was registered continues growth. GDPgrowth 10.7 percent and the average annual inflation was 9.9 percent. Here, to sustain this rapid economic growth with stable and moderate prices sound macroeconomic management is required. To this end, examining the dynamics of inflation has a premanet importance, (NBE, 2003).

\subsection{Statement of the problem}

Ethiopia as one of the developing country is highly faced with soaring inflation. According to NBE (2007) report inflation has been contained in advanced economies, but it was risen in many emerging and developing countries, reflecting higher energy and food price. That is inflation in advanced economies is expected to decline to 2.1 percent in 2007 while inflation in a emerging markets and developing countries is to rise to 5.9 percent from 5.1 percent in 2006. Likewise, inflation in Ethiopia has been a burning issue that affects a society at large. An important source of welfare deterioration in Ethiopia has been food price inflation. According to (Audient, 2006). The largest percentage of inflation account with food inflation a currently food price are increasing more rapidly in the world in general in particular.

This crisis has become a series global problem where in some place price of food have increased by more than 20 percent within two years leading to violence and conflict (FAO, 2007). This food price volatility is because of the seasonal UPS and downs of agricultural production shock. in march, 2008, inflation has risen to 29.9 percent. Form which food price inflation accounts above 40 percents.(World Bank, 2008). This is very high compared to the previous period.Inflation has been contentious subject throughout history. Different theories have been forwarded by economists as to the cause of inflation. The monetarists contended that money supply is the most important determinant of inflation. As Milton Friedman put it "inflation is always and everywhere monetary phenomena and can be produced only by a more rapid increase in the quantity of money than output" on the other hand stracturalist argue that structural rigidities such as supply inelasticity, budgetdeficit, rainfall, government policies, poor infrastructures, etc as the root cause of inflation in developing countries (Mcvaish, 2000).

For many countries industrialized and developing the most fundamental objective of macroeconomic polices is to sustain high economics growth with low inflation.

In this regard the Ethiopian economy has made great strides to wards achieving a rapid economy growth which continued for the sixth time in a row in 2008/09 putting the economy in a high growth trajectory. With all $42.6 \%$ share in GDP, agricultural and allied activities rose by $6.4 \%$ contributing $27.2 \%$ to the overall economic growth recorded in the fiscal year of 2008/09. but this has not been with challenge. Inflation has been steadily increasing in double digit percentage point in fiscal year between 2005/06 and 2008/09. In the 2008/09 fiscal year inflationary pressure was major problem which was primarily attributed to structural transformation in the domestic economy, growing demand Hikes in world commodity. Accordingly, annual average headline inflation reached $36.4 \%$ which was $11.1 \%$ higher than the fiscal year of $2007 / 08$. this was largely attributed to the increase in the price of food items whose combined contribution reached $8.8 \%$ percentage points while non-food item made up the remaining $2.3 \%$ annualized average food inflation which constitutes $57 \%$ of the CPI reached $44.2 \%$ and $9.4 \%$ higher than that of last year mainly due to significant rise in the price of cereals, potatoes other tuber and stems and pulses which together accounted for 35.4 percentage point of the records rate. Annualized non-food inflation was also high unlike previous years which was due to the surge in the rate of inflation of house rent, construction materials, water fuel and power, clothing and foot wear, and furniture furnishing, household equipment and operation which jointly account for $75 \%$ of the expenditure on consumption of nonfood items. Nonfood inflation rose to its highest level 23.8\% in 2008/09(national bank annual report, 2008/09)

As can be seen from the above discussion inflation has been rising at an alarming rate for the past seven years its effect have been devastating for the urban poor and rural population as their purchasing power has been decaling drastically. Although the government has taken measure of price stability, inflation is still rampant in Ethiopia, (Ibid),

There is methodological difference in the past and the present studies the past researcher was utilize OLS econometric model while in the present study I was employed structural VAR econometric model and these model includes two basic components those have been impulse response function and forecast variance decomposition error since, there are no quantitative studies that we aware of on structural rigidity for Ethiopia by considering these things. 
I was a study does structural rigidity influence output and inflation or does it impact on the economy? Are the key issues that have not yet been empirically analyzed? Therefore in empirical investigation of these issues appears very urgent as it have important policy implications for improved performance of the Ethiopia economy. This present study was important in that it give an insight as to the cause of inflation. in doing so, it provides suggestion on taking socio economic problem in addition to these study was benefits these who read this papers and they would be aware of about the determinants and they can find the solution of those problems.

\subsection{Objective of the study}

\subsubsection{General objective}

The general objective of the study is to identify the root causes of inflation in Ethiopia.

\subsubsection{Specific objectives}

This paper would have the following specific objectives.

- To investigate the determinates of inflation in Ethiopia.

- To provide suggestions and recommendations on how to curb this problem

\subsection{Hypotheses of the study}

There are arguments that what could be cause of inflation in developing countries. Some argues that it is by persistent growth of money supply while other argues that it is caused by other structural factors as the debate so on. Inflation is caused when the aggregate demand exceeds the aggregate supply of goods and services, so the hypothesis to be tasted in the paper would be.

In the researcher it is expected that the dependent variable inflation has the following relation with the explanatory variables. Real money growth and budget deficit has positive relationship with inflation while real gross domestic product and real effective exchange rate has expected negative relationship with inflation.

\subsection{Significance of the study}

Inflation has many ramifications. It has adverse impact on income distribution, future profitability of investments, the price of exports, economic growth and moreover it decrease the purchasing power if individuals. This paper is important in that it give an insight as to the cause of inflation. In doing so, it provides suggestions on tackling this socio-economic problem.

\subsection{Methodology}

\subsubsection{Model specification}

There have been different theories as to the cause of inflation. The monetarist and structuralist theories of inflation are two of the most prominent.

Based on these theories the study will consider some of the variable will be include in the literature review part of the study.

LOGCPI $=\beta$ o $+\beta 1$ LOGRMS $+\beta 2$ LOGRGDP $+\beta 3$ LOGREER $+\beta 4 \mathrm{LOGBD}+\mathrm{Ui}$

The above variable can be further elaborated up on

$>$ INF is inflation rate measured by the change in the consumer price index(CPI).

$>$ RMS is realmoney supply.

$>$ RGDP real gross domestic product

$>$ REER is real effective exchange rate

$>$ BDbudget deficits

1.5.2. Data

$>$ Bois the constant term ' $t$ ' is the time trend and Ui is the random error term.

This study is based on secondary data acquired from various organizations including the national bank of Ethiopia (NBE), central statically Agency (CSA) and various research documents.

The study will use econometric model to analyze the time series data of inflation as a function of different variables. The data was test for stationary and co-integration. The time span under consideration is 1980 to 2013 period.

\subsubsection{Estimation techniques}

There are different models in econometrics but I was employed the structural VAR model.

Before we estimate the system that govern the relationship among real money supply, real effective exchange rate, real gross domestic product, Budget deficit and inflation, we check for the order of integration of these variables. The model which was employed in this paper is the co-integration and Error correction model (ECM). It is because the time series data are non stationary in their nature. K Paterson (2000) has noted that in real life non- stationary is common in macroeconomic time series such as income, consumption money supply, inflation, trade data and soon where their mean, variance and covariance are time variant that is they vary with time. If the data series are found to be non stationary most of the classical assumption for econometric estimation and forecasting are violated. So, treating non- stationary series as if they were stationary will lead to a misleading to a problem of spurious, a 
situation where exogenous and endogenous variables are Random walk but not co-integrated. Spurious regression with a non stationary series that renders what are called non -sense result. This because variables that are likely to be non-stationary will have stochastic trend, and where are variables share a trend it will be difficult to get the true relationship from the trend influence. Thus, to avoid this non-stationary problem and false conclusion, a co integration analysis is essential, where differencing was taken to reduce non-stationary to staionarity.Acording to k. Paterson (2000) the co-integrating coefficients are the linear combination, which reduce the non- stationary to stationary. A time series data is to be stationary if its mean, variance and auto covariance at varies lag -remain the same no matter at what time we measure them (Guajarati,1995).Thus, in the study a unit root test ,AugmentedDucky Fuller(ADF)test, wasemployed to know the order of integrations and number of lags of variables, where weather there is arejection of null hypothesis or not.(Guajarati2004)

\subsubsection{Unit root test}

Since time series generally exhibit a non-stationary pattern on their levels unity root testing, as a pretesting device for co- integration was carried out in order to determine the degree of stationary. As noted above to test whether data series are stationary or non - stationary the augmented ducky fuller (ADF) test will employ. This test relies on rejection the hypothesis that the series is a random walk in favor of stationary. The basic criterion under this test is to know the order of integration before the date series become stationary. As (Guajarati, 1995) noted that a series is said to be integrated of order "zero" or at level if it became stationary without differencing, I(0), if it became stationary at order one $\mathrm{I}(1)$, or differencing once it is called integrated of order one or series is said to be integrated of order $\mathrm{K}$, if it becomes stationary after differencing it ' $\mathrm{K}$ ' times.

ADF test requires a negative sign and significant test statistic according to (Gujirati, 1995), D. astrious and Stephen (2007), if the ADF statistic value in absolute tern exceeds the critical value at $1 \%$ or $5 \%$ or $10 \%$ level of significance, we reject the null hypothesis and then conclude that the variable is stationary. In this model there is a possibility to regress non stationary variables in levels. this would to get the long run information embodies in the integrated variables.

We use a two-step procedure of Engle-granger to carry out co integration test. the steps as follows.

$>$ Run abivariate OLS regression in level and save the residuals

$>$ Based on the ADF test, see whether the residual have all it root.

$>$ if the error term of this relationship is stationary then we say that the integrated variables are co-integrated.

$>$ the error term of this relationship will be use to contract a dynamic error correction model which captures the long rue of well as a short run dynamic of the model.

\subsubsection{CO- Integration test}

This test is always carried out after a unit root test on the residuals of the long run static regression in order to find out whether there exists a long run relationship between the regress and the regress or. It is a way to obtain both short run dynamics and long run relationships. As (Gujirati, 2004) pointed out that variables are said to be co integrated if they have along run or equilibrium relationship between them and a test for co-integration can be thought as a pretest to a void spurious regression situation. If two variables are co-integrated then we can estimate their relationship by least square, because the error term is stationary by definition and least square provide unbiased and consistent estimates of the co-integrated parameter( astorious and G.Hall, 2007).In order to determine the long run relationship between the variablesJohnson and Engel granger co -integration test was employed.

To set whether two variables are co-integrated, we can simply estimate their relationship by least squares and test to see whether the residuals have a unit root using ADF test.

Co-integration provides a means of parting there valuation of time series data in to its components.

$\checkmark \quad$ Long-run equilibrium characteristics

$\checkmark$ Short-run disequilibrium dynamics

Thus if the ADF test foe residual stationary failed to reject the null prosthesis, then it leads to an error correction model to make adjustment in time.

The long run effect is given when the model is in equilibrium and specified as;

$$
y_{t}=\beta_{0}+\beta_{1} x_{t}
$$

\section{Error Correction Model (ECM)}

To coverage (show) the long run model in to two components error-correction modeling is used.

The unit root and co-integration test conducted in previous section showed the existence of long run and short run relationship among the variables. Thus, having concluded that variables in the VAR model appeared to be co integrated, we proceed to estimate the short run behavior and the adjustment to the long run models, which is represented by ECM.Error Correction Method (ECM) is called the speed of adjustment term. This measures the short-run adjustments of the deviations of the independent variables from their long- run values. It shows that how much time would be taken by the economy to reach at long run equilibrium. Negative sign of speed of adjustment term shows that the economy will converge towards long run equilibrium and positive shows the economy will not converge to the long run equilibrium.Having already obtained the long run model and estimated co efficient 
the next step is estimating the coefficient of the short run dynamics by ECM. ECM shorts the short run relationship between the variables. This adjustment towards the equilibrium is made by combining the long run and short-run versions of the model in one regression. The error term of this relationship will be used to contract a dynamic error correction model which captures the long run of as well as a short run dynamic of the model.

\subsubsection{Model Selection criteria}

Guajarati (1995) D. Asterious and G.Hall (2007), K.Paterson (2000) had noted a set of criteria in order to specify a true model from least square method of measurement. accordingly they valued $\mathrm{R}^{2}$, Adiusted $\mathrm{R}^{2}\left(\mathrm{R}-{ }^{2}\right)$, Akaike information (AIC), Schauartze information (SIC), F-static and DW(d) values at what value the true model is selected. so according to them, the closer to one is the better to fit for $\mathrm{R}$ and adjusted $\mathrm{R}^{2}\left(\mathrm{R}^{2}\right)$ and the better to fit for $\mathrm{R}^{2}$ and adjusted $\mathrm{R}^{2}\left(\mathrm{R}^{2}\right)$ and the lower the AIC and SIC. The better is model.

\section{Literature Review}

Up till now different theories of inflation have been discussed. Consequently, we look at some of the determinants of inflation that are observed in Ethiopia and other countries. A work by Kejela (2005) tried to show the determinants of inflation in Ethiopia. His findings should money supply as the major cause of inflation. It indicated that $60 \%$ of the variation in inflation is explained by money supply. The second most important determinant was found to be price expectation peroxide by one year lag inflation $44 \%$ of the variation in inflation was caused by price expectation. Real GDP was also important in determining inflation. It resulted in $35 \%$ of the inflationary process in Ethiopia.

A similar work by Bezaye (2009), tried to explain the determinant of inflation in Ethiopia. In the long run the study found money supply to be the number one determinate of inflation. It was found that $65 \%$ of the inflation is explained by the change in money supply. Real GDP should a negative relationship with inflation while price expectation had a positive relationship with each variable explaining about $13.8 \%$ and $45 \%$ of the change in inflation respectively. In short run, an even, stronger relationship. Was found between money supply and inflation.

An increase in money supply by $1 \%$ resulted in $71 \%$ increase in general price levels. Government deficit was also found to be important in determining inflation in the short run. Olubusaye and Oyaromade (august, 2008) tried to investigate the determinate of inflation in Nigeria. In their study, they used the frame work of the error correction model to identify the determinates of inflation in the short run. The results of the model indicated that expected inflation, rainfall, petroleum price and real exchange rate to be the most important variable in the inflationary process.Expected inflation and petroleum price peroxide by a one year lag had apositive effete on inflation with 0.13 and 0.037 as their elasticity's rainfall lagged by one year period also played a significant role in determine inflation. Its coefficient showed that good whether in the previous year would reduce inflation by $11.1 \%$ real exchange rate was also found to significantly affect inflation its coffined is indicated that $1 \%$ depreciation caused an $8 \%$ increase in inflation. Real exchange rate peroxide by a one year lag had a negative effect on inflation in their long run model, they found money supply and fiscal deficit to significantly affect inflation.

In their 2007 work khan, Bukhari and Ahmed tried to identify the cause of inflation in pakistan using a multiple regression model. They included government sector borrowing as a ratio of GNP, real demand relative real supply non-government sector borrowing as a ratio of GNP, price index of imports, exchange rate, government taxes as a ratio of manufacturing sector value added. Lagged CPI and support wheat price as independent variables and too. CPI as a dependent variable. All the variables were found to be significant with elasticity's of $0.10,0.123,0.18,0.12,0.14,0.22,0.40$ and 0.10 respectively. These result indicated government taxes as the ratio of manufacturing sector lagged CPI and non-government borrowing as a ratio GNP to be the most important determinants of inflation in Pakistan.

\section{Results \\ Estimation and interpretation of regression results \\ I. Test for stationary}

As it was explained in methodology part under estimation techniques, ADF test was employed, in this study, to test wither the variables are stationary or not ADF-test helps us to determines at what order of integration the variables become stationary and the length of lag as well. Thus, the tests of integration of order zero are carried out on the level and the first difference of the variables respectively. In this study the ADF result show that all variable become non stationary at level but all variables become stationary at first difference. This means the ADF test rejects the nll hypothesis of unit root (non stationary) and concludes that co integration test can be carried out to determine the long run estimation equation. Therefore, according to the ADF test the model shows only the short rune relationship between the variables. The resulted of the where the time variable of the data stationary or not given by the below table tested by the ADF unit root test.

Hypothesis is $\mathrm{H}_{0}=$ is non-stationary or unit root 
Table $-1 \mathrm{H}_{1}=$ otherwise reject $\mathrm{H} 0$ accept $\mathrm{H} 1$ stationary.

\begin{tabular}{|l|l|l|l|l|}
\hline \multirow{2}{*}{ Variables } & Level of intercept & Intercept +trend \\
\cline { 2 - 5 } & T-statics & Probability & T-statics & Probability \\
\hline CPI & 1.31 & 0.99 & -0.67 & 0.96 \\
\hline RMS & -0.51 & 0.87 & -3.49 & 0.05 \\
\hline RGDP & 4.42 & 1.00 & 0.53 & 0.99 \\
\hline REER & -1.49 & 0.52 & -1.42 & 0.83 \\
\hline BD & 1.54 & 0.99 & -0.84 & 0.55 \\
\hline
\end{tabular}

Table -2 ADF unit root first for stationary on the $1^{\text {st }}$ difference is listed below.

\begin{tabular}{|l|l|l|l|l|}
\hline \multirow{2}{*}{ Variables } & Level of intercept & Intercept +trend \\
\cline { 2 - 5 } & T-statics & Probability & T-statics & Probability \\
\hline CPI & -5.03 & 0.0003 & -5.36 & 0.0007 \\
\hline RMS & -5.92 & 0.00000 & -5.79 & 0.0002 \\
\hline RGDP & -3.26 & 0.0249 & -4.38 & 0.0077 \\
\hline REER & -4.52 & 0.0010 & -4.47 & 0.0061 \\
\hline BD & -4.97 & 0.0003 & -5.22 & 0.0009 \\
\hline Level of 10significance & crtical value \\
$1 \%$ & -3.646342 & \\
$5 \%$ & -2.954021 & \\
$10 \%$ & -2.61587 & & \\
$10 \%$ & -2.61587 &
\end{tabular}

Unit root test revealed that all variables used in their study is integrated order one I(1). Thus, the determination of co integrating relationship does not suffer from mixed order of integration. The existence of co integrating vectors in the model will now be tested using Johansson's approach.

\section{II.Co integration analysis}

As noted above the determination of the co- integrating relationship in the model is done using the VAR (Vector auto regressive) based Johansen`s approach. An important limitation of the VAR approach is that it is not suitable for models was large numbers ofvariabels. This is because the persistence of lags of the variables in the system requires estimation of large number of cofficents. The degrees of freedom in estimating the coefficients will be low and the estimated cofficents, thus, will be inefficientMoreover, the interpretation of the co- integrating space become difficult (Juselius, 1992). Following Juelius (1992,. In this study, therefore, the long run relationships would be derived using sectoral VARS. In determining the number of co integration relationships the lag length used is two as determined using various information criteria table 3 below show that results from various VAR lag length selection criteria used in determining the lag length of the model.

Table 3 VAR lag order section criteria

\begin{tabular}{|c|c|c|c|c|c|c|}
\hline Log & $\log \mathrm{L}$ & LR & FPE & AIC & SIC & HQ \\
\hline 1 & 191.7353 & NA & $2.08 \mathrm{e} 011$ & -10.42095 & $-9.2758^{*}$ & -10.04138 \\
\hline 2 & 230.5707 & $53.3167 *$ & $9.66 \mathrm{e}-12^{*}$ & $-11.28192 *$ & -8.991700 & $-10.52278^{*}$ \\
\hline \multicolumn{7}{|c|}{$\begin{array}{l}\text { - Indicates log order selected by the criteria } \\
\text { LR* is sequential modified LR tests static } \\
\text { AIC is Akaki information criteria } \\
\text { SIC Mean Schwarz information criteria } \\
\text { HQ HananQuinen information criteria }\end{array}$} \\
\hline
\end{tabular}

As can be seen from the table above LR, FPE and HQ criteria indicates that the appropriate lag length is two Johnsen procedure test result for co integration with two lags in the system indicates that there are two co integrating relationships. Both trace and maximum Eigen value test fail to reject the null of at most two cointegrating equation in the system. The trace of maximum Eigen value and trace statics given below.

Table 4 Johanse co-integration test result

\begin{tabular}{|c|c|c|c|c|c|c|c|}
\hline \multirow[t]{2}{*}{$\mathrm{HO}$} & \multirow{2}{*}{$\begin{array}{l}\text { Eigen } \\
\text { values }\end{array}$} & \multicolumn{3}{|l|}{ Trace statistics } & \multicolumn{3}{|c|}{ Maximum Eigen values } \\
\hline & & $\begin{array}{l}\text { Johensen`s test } \\
\text { statistics }\end{array}$ & $\begin{array}{l}\text { Critical } \\
\text { values }(5 \%)\end{array}$ & Prob & $\begin{array}{l}\text { Johensen`s test } \\
\text { statistics }\end{array}$ & $\begin{array}{l}\text { Critical } \\
\text { values }(5 \%)\end{array}$ & Prob \\
\hline $\mathrm{H}=\mathrm{O}$ & 0.669041 & 76.97916 & 69.81889 & 0.0120 & 35.38435 & 69.81889 & 0.0120 \\
\hline $\mathrm{H} \leq 1$ & 0.489592 & 41.59481 & 47.85613 & 0.1704 & 21.52145 & 47.85613 & 0.1704 \\
\hline $\mathrm{H} \leq 2$ & 0.289463 & 20.07336 & 29.79707 & 0.4179 & 10.93550 & 29.79707 & 0.4179 \\
\hline $\mathrm{H} \leq 3$ & 0.202868 & 9.137858 & 15.49471 & 0.3528 & 7.255520 & 15.49471 & 0.3528 \\
\hline $\mathrm{H} \leq 4$ & 0.057126 & 1.882338 & 3.84166 & 0.1701 & 1.882338 & 3.84166 & 0.1701 \\
\hline
\end{tabular}

Result of the long run mode shows that there is along run relation shipamong the variables orit is one co - 
integrating equation because at most 1 in the table it cannot reject the null hypothesis that means the null hypothesis at most one reflects there is a one cointegrating equation among variables.

In order to estimate the long run model of inflation in Ethiopia, the Johansen`s co-integration test was also employed.

Table 5 result of the long run model (standard error in parentheses)

\begin{tabular}{|l|l|l|l|l|l|}
\hline Variables & Constant & Log RMS & Log GDP & Log REER & Log BD \\
\hline Coefficients & 1,000 & 1.4435 & 1.267928 & -0.719373 & -1.527644 \\
\hline
\end{tabular}

As table 5 shows that about 1.44 percent of variation in inflationary situation is explained by money supply. It asserted the theory of monetarist that inflation is a phenomena of money supply everywhere and any time. But the regression results does not support the monetarist assertion that a percentage increase in money stock will lead to unique proportional change in inflation. The response of inflation rate to aunit increase in money supply is less than unity in increase inflation in Ethiopia.

The coefficients of real GDP growth with a positive sign but the sign was expected to be negative but its test result is positive which postulated that the increase on RGDP growth do increase inflation rather than it decrease inflation in Ethiopia. It is because of the fact that the excess demand of output (goods and services out weights the supply of them. This ascertained the theory of demand pull inflation where it postulates, inflationary pressure arise because of excess demand for goods services result from expansionary monetary and fiscal policy.

The long run equation shows as real effective exchange rate (REER) negatively explain inflationary problem. The study found that budget deficit in Ethiopia case it affects inflation negatively because of the fact that the deficit financing is not by printing money and borrowing rather by external aid relief.

\section{Engel Granger two step approach}

The first approach that the Engle Granger is begins by testing whether the variables of interest are stationary or not. If the variables are completed in the model follow an $\mathrm{I}(1)$ process, the first step is estimate the long run equilibrium equation using OLS method and ADF test on the residual of the long run equation is conducted to determine if the variables are co integrated that is whether the error term follows stationary process. If that is the case, it is taken as a proof of co integration (AlemayehuGeda et al, 2001).

\section{Engel Grange Error Correction Model}

The error correction model (ECM) indicates the short-run dynamics of the OLS estimation results and its adjustment towards the long-run equilibrium. ECM removes non-stationary from the individual series in order to make the conventional classical regression techniques applicable and to correct the disequilibrium error created in the short term

Estimating the first differences of the dependent variable on the first difference of the independent variables using OLS shows the short term dynamics of the model but we can use the one period lagged error term to tie the short-run behavior of the dependent variable to its long-run value (Gujurati, 1995).

Having already obtained the long run estimated coefficients, the next step is estimating the coefficients of the short run dynamics by Error Correction Model. Error Correction Model shows the short run relationship between variables. This helps to show the deviation from the equilibrium position and how the adjustment towards the equilibrium is made by combining the long run and short run versions of the model in one regression. Since all variables are stationary at first their difference the estimation result is below and that the ECM is stationary at level and the $t$ statistic is greater than the significance levels in absolute term. 
Table .4 short run regression analysis

Dependent Variable: D(LNCPI)

Method: Least Squares

Date: 06/03/15 Time: 15:03

Sample (adjusted): 19812013

Included observations: 33 after adjustments

\begin{tabular}{crlrr}
\hline \hline Variable & Coefficient & Std. Error & t-Statistic & Prob. \\
& & & & 0.6183 \\
C & 0.029073 & 0.057676 & 0.504078 & 0.0252 \\
D(LNRMS) & -0.571036 & 0.240989 & -2.369550 & 0.0228 \\
D(LNRGDP) & 0.425048 & 0.176009 & 2.414922 & 0.7223 \\
D(LNREER) & -0.037355 & 0.104010 & -0.359143 & 0.5550 \\
D(LNBD) & 0.240577 & 0.402465 & 0.597758 & 0.0059 \\
ECM(-1) & -0.470377 & 0.157193 & -2.992347 & 0.078288 \\
& & & & -123742 \\
R-squared & 0.552834 & Mean dependent var & & -1.5413201 \\
Adjusted R-squared & 0.470025 & S.D. dependent var & & 6.676040 \\
S.E. of regression & 0.090083 & Akaike info criterion & & 0.000363 \\
Sum squared resid & 0.219104 & Schwarz criterion & & \\
Log likelihood & 35.91781 & F-statistic & & \\
Durbin-Watson stat & 1.853788 & Prob(F-statistic) & & \\
\end{tabular}

Source: from strata

Note; ECM (-1) is lagged Error Correction Model term saved from the estimated long run equation.From table above ECM (-1) is significant because the probability is less than 5\% which is 0.0057 and its coefficient is negative, this is a good sign which implies there is a long run relationship (association) but the other coefficients of the explanatory variables are short run coefficients. Its magnitude of ECM(-1)coefficient) indicates that the $47 \%$ of the disturbance in the short run will be corrected each year. The coefficient of determination (R-squared) indicates that $55 \%$ of inflaton is explained by the variables included in the model. The result reveals that all the variables in the dynamic short run model, except REER and BD are insignificant.

After taking ECM there are further test for the ECM (-1) such as serial correlation and normality test.

\section{Auto (Serial) Correlation Test for ECM (-1)}

If the residual are correlated among them, this correlation is called auto (serial) correlation, one has to look for pattern of this correlation is Durbin-Watson stat on the regression table and the other test is by using BrueschGodfrey Serial Correlation LM test. The guide line of Durbin-Watson stat is said to be if the Durbin-Watson stat is near to two the residuals are not serially correlated, otherwise it suffers from serial correlation. The other mechanism of testing serial correlation among residuals is Bruesch-Godfrey Serial Correlation LM test and his guide line is if the Obs*R-squared probability is greater than 5\% there is no any serial correlation.

In this estimation Durbin-Watson stat is 1.8341 andObs*R-squared probability is 0.305 which is greater than $5 \%$, therefore the model free from serial correlation. 
Serial correlation

Breusch-Godfrey Serial Correlation LM Test:

\begin{tabular}{lllr}
\hline \hline F-statistic & 0.967957 & Probability & 0.393644 \\
Obs*R-squared & 2.371746 & Probability & 0.305479 \\
\hline \hline
\end{tabular}

Test Equation:

Dependent Variable: RESID

Method: Least Squares

Date: 06/03/15 Time: 15:06

Presample missing value lagged residuals set to zero.

\begin{tabular}{crrrr}
\hline \hline Variable & Coefficient & Std. Error & t-Statistic & Prob. \\
\hline \hline C & 0.012980 & 0.058496 & 0.221903 & 0.8262 \\
D(LNRMS) & 0.026842 & 0.242389 & 0.110739 & 0.9127 \\
D(LNRGDP) & 0.001220 & 0.179733 & 0.006791 & 0.9946 \\
D(LNREER) & -0.063570 & 0.123658 & -0.514079 & 0.6117 \\
D(LNBD) & -0.121000 & 0.413788 & -0.292421 & 0.7724 \\
ECM(-1) & 0.026787 & 0.281952 & 0.095007 & 0.9251 \\
RESID(-1) & 0.105590 & 0.386645 & 0.273092 & 0.7870 \\
RESID(-2) & -0.313795 & 0.243207 & -1.290237 & 0.2088 \\
\hline \hline R-squared & \multirow{2}{*}{. } & & $6.73 \mathrm{E}-18$ \\
Adjusted R-squared & 0.071871 & Mean dependent var & & 0.082747 \\
S.E. of regression & -0.188005 & S.D. dependent var & & -1.766573 \\
Sum squared resid & 0.090190 & Akaike info criterion & & -1.403784 \\
Log likelihood & 0.203357 & Schwarz criterion & & 0.276559 \\
Durbin-Watson stat & 37.14846 & F-statistic & 0.957318 \\
\hline \hline
\end{tabular}

\section{Normality test}

Test for normality means determining whether the error term is normally distributed or not. This test for normal distribution taken by using Jarque-Bera test, this indicates the error term is normally distributed because the probability is greater than $5 \%$. 


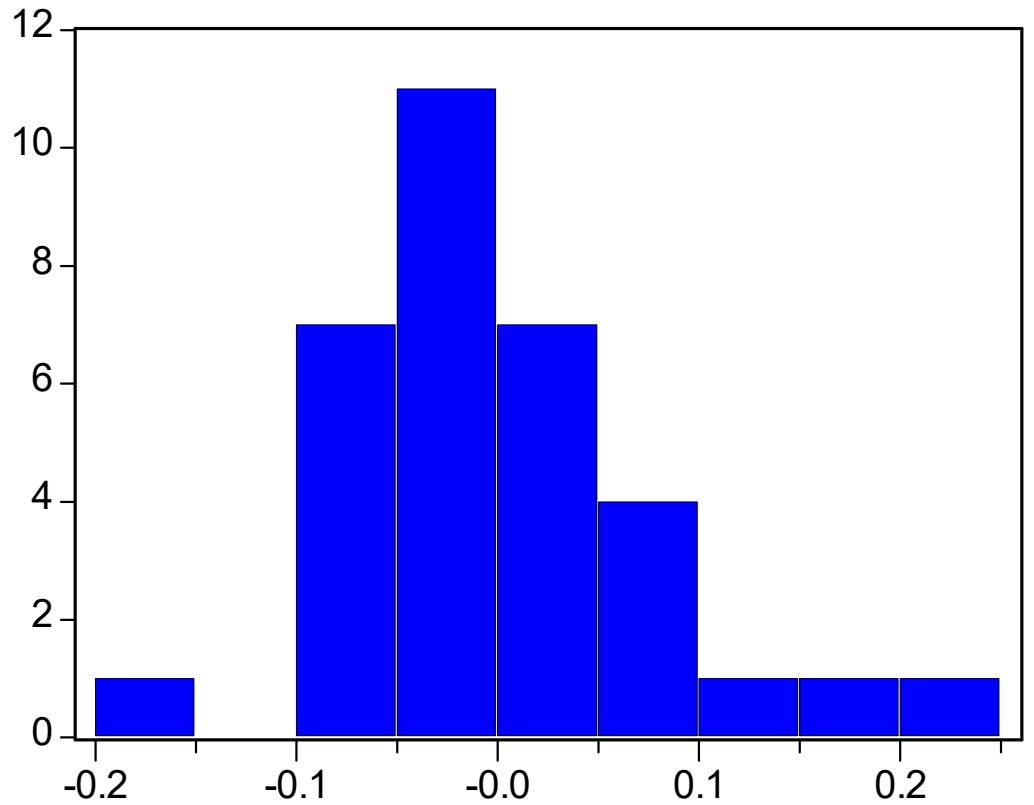

\begin{tabular}{|lc|}
\hline \multicolumn{2}{|l|}{ Series: Residuals } \\
Sample 1981 2013 \\
Observations 33 \\
Mean & $6.73 \mathrm{e}-18$ \\
Median & -0.009787 \\
Maximum & 0.242042 \\
Minimum & -0.188492 \\
Std. Dev. & 0.082747 \\
Skewness & 0.714940 \\
Kurtosis & 4.228522 \\
& \\
Jarque-Bera & 4.886504 \\
Probability & 0.086878 \\
\hline
\end{tabular}

Interpretations of short run Dynamics Model

The short run analysis indicates that the error correction model explains about $47 \%$ of the change in inflation.

Out of the variables REER and BD were found to be insignificant inexplaining inflation in the short run. RGDP and RMS was found to be significant at 5\%. However RGDP and RMS were not found with their expected sign. The sign of RMS was the most surprising result because it is in contrast with the monetarist theory that asserts appositive and proportional relationship between money supply and inflation.

Economic theory postulated that GDP growth in the period "t" leads to reduce inflation. This means when there is a good performance in agricultural production and the supply of food (which accounted bout $50 \%$ inflation in Ethiopia). Increase in the market there by inflationary problem decrease. But this theory does not hold true for the case of short run where our result shows that GDP and inflation has positive related rather. In this case the demand pull theory is applicable where excess demand effects in price from real output are more important than the supply of GDP to the market or monetary effect.

More-over, F-test shows that the exogenous variable will explain the dependant variable, inflation. Among the variable included in the short run model real GDP and RMS a significant role in the inflationary process in Ethiopia.

\section{Impulse Response Function}

Impulse responses ascertain the responsiveness of the dependent variable in the VAR to shocks to each of the variables. A shock to one variable not only directly affects that variable but is also transmitted to all of the other endogenous variables through the dynamic (lag) structure of the VAR. An impulse response function traces the effect of a one- time shock to one of the innovations on current and future value of the endogamous variable. Impulse response analysis is astandard tool for investigating the relation between the variables in a VAR model. It traces the effect of a one standard deviation shocks to one of the innovations on current and future value of the dependent variables through the dynamic structure of the VAR. AStandard choleski decomposition is used in order to identify the short run effects of shocks on the levels of the endogenous variables in the vector error correction model.

Impulse responses are presented in Appendix (1) with the cholesky ordering CPI, RMS, RGDP REER, and BD. The $\mathrm{X}$ - axis gives the time horizon or the duration of the shock while the $\mathrm{y}$ - axis gives the direction and intensity of the impulse or the percent variation in the dependent variable away from its base line level. Equivalently it is also presented from table in (Appendix).

From left to right the first figure ( Table 11) shows the responses of CPI, RMS, RGDP, REER and BD with respect to one standard devation innovation in CPI. The result indicates one positive shock to inflation leader to appositive response from inflation (CPI), RGDP and REER while the shock to CPI from RMS and were somehow is negative.

\section{Forecast Error variance Decomposition}

Variance decompositions offer a slightly different method for examining VAR system dynamics. The decomposition used to understand the proportion of the fluctuation in series explained by its own shocks from other variables. A shock to the $i^{\text {th }}$ variables in the system through the dynamic structure of the VAR. The variance decomposition of the VAR model gives information about the relative importance of each of the random 
innovations in explaining each endogenous variables in the system in general it is expected a variable to explain almost all its forecast error variance as a short horizons and smaller proportion at a longer horizons.

The result of the decompositions of the ending our variables of the model are presented from (Appendix 2) Table 6 up to Table 10 and plotted in figure 3. These two results provide the percentage of the forecast error in each variable that could be attributed to innovation of the other variables for different time period with the cholesky ordering CPI, RMS, RGDP REER and BD.

The variance decomposition analysis result in the third figure of raw 1 Appendix -2 of Table 6 show that at the first horizon variation of CPI explained only by its own shocks. In the second period 97.1 percent of the variability in the CPI fluctuation is explained by its own innovation. The proportion decrease for the following period to 78.77 percent after ten periods. RMS and BD shocks increase the percentage as the contribution of CPI. Shock decrease and its reaches 78.77 percent. This implies RMS and BD have better performance in explaining the long run shock of CPI in Ethiopia. The contribution of RGDP and REER is very little and constant. The role of RGDP shocks is not significant in determining inflation of Ethiopia.

At the figure 3 row (2) in the variance decomposition Table 7 in the first round 60.3 percent changes in RMS resulted from the shocks of its own innovation. The remaining 36.69 percent comes with CPI. This shock has caused REER BD and RGDP to change at a constant level. In the second period 55.5 percent change in RMS level resulted from the shock to the RMS innovation and the remaing 48 percent's shocks comes with CPI innovations. Thus the role of Ethiopian inflation shock is better in determine the RMS shocks. For RGDP in the first round (Table 8) 53.555 percent variation of RGDP resulted from the shock of its own innovation and 33.88, 12.55 percent variation in resulted from the change in CPI and RMS respectively and the remaining is the change in other variables. In the long term CPI RMS and BD can explain 54.82, 15.885 and 6.52 percent forecast variance of RGDP, respectively and 18.6599 percents variation of RGDP is resulted from the shock of its own innovation. This show that CPI and RMS are a principal component in determining Ethiopian RGDP shocks in the long run.

For REER in the first round table 9 Appendix (3) 81.28 percent variation of REER resulted from the shock of its own innovation and the remaing 12,385 and 5.78 percent variation comes from RMS and CPI. RGDP and BD cause very low and constant on REER shocks.

In the long term CPI RGDP and RMS shocks are the main determinants of Ethiopian inflation shocks with $18.32,10.34$ and 6.4 respectively. Based on Table 10 for BD in the first round 76.55 percent a shock comes from itself and the rest is from other variables. In the medium and long term the key determents of BD shocks is itself but REER has no importance and significant variability in determing BD shocks. This implies in the long run the variability of BD can be explained by shocks of itself, CPI, RGDP, BD of Ethiopian shocks has constants variability REER. Whereas RMS is a little impact on the shocks of BD in the long run.

\section{Diagnostic Test Interpretation}

Diagnostic tests were conducted to test the adequacy of the model. The model satisfies all diagnostic test. Autocorrelation tests indicate that there is no problems of autocorrelation. The null of no serial correlation at lge order of 12 can not be rejected using LM test. Moreover, the residuals of the model are homoskedastics as the null of homoskedasity residuals can not be rejected using white Heteroskedasity (with cross terms)test. Jarque-bera test of residual normality can not reject the null of multivariate normal residuals implying that the residual of the model are also normally distributed. Inverse $\operatorname{root}(\mathrm{AR})$ characteristics test shows stability of the economy and the variable put in the circle of stability condition these achieved through differencing at once or I (1) in their model.

\section{Conclusion and Recommendation}

Ethiopia has been known for its low inflation. It experienced an average inflation rate of $4.7 \%, 9.5 \%$ and $4.9 \%$ during. The imperial the derg and the current government. However in recent time inflation has been running out control.This study has investigated the root cause of inflation in Ethiopia. In doing so it aims to give a clear understanding of the factors. That are at work in the inflationary process. In order to do this a regression model was applied in which inflation is taken as the dependant variable and treated as a function RMS, RGDP, REER and BD (budget defict).

The conclusion of this study can be listed as follows:

One of the variables money supply was found to be the most significant determinants of inflation in the long run. This in line with the monetary theory of inflationYet this does not correspond to the assertion that money supply and inflation rise in an equal and proportional manner. According the study found budget deficit is insignificant to determine inflationary process in Ethiopia case. The insignificant impact budget deficit on inflation in Ethiopia case may be because of the fact that the deficit financing is not by printing money and borrowing rather by external relief.

Using co integration analysis the study found that money supply real GDP growth real effective exchange rate, (REER) and budget deficit (BD) are significant to determine inflation in the long run. While in the short run BD and REER are insignificant to determine inflation in Ethiopia. The sign of the coefficient for money supply and REER is as expected that signify the strong relationship between inflation and those variables. Were as, the sign 
of RGDP growth and budget deficit is the inverse of the expected. This leads to assess other possibilities other than economic theory predicts directly. Regarding to the positive sign of RGDP, as explained the interpretation part, the demand pull effect of inflation could ascertain this positive relation. The demand pull theory postulated that inflation pressure rises because of excess demand for goods and services resulting from expansionary monetary and fiscal policies.

\section{Policy Recommendation}

In conclusion if the government wants to achieve economic growth with low inflationary pressure, it should take up the following policies.

Adopting of restrictive monetary policy. This policy enables the government to reduce stock of money in circulation there by it can reduce inflationary problem.

1. To reduce the impact of RGDP on inflation, the country should achieve the supply and demand equilibrium of RGDP in the market. This can be achieved through expansion of investment in the country. On other hand

2. Close attention to the growth of RGDP. so that the economy does not over -heat.

3. Again to reduce the impact of exchange rate on Ethiopian inflation, domestic industry should expanded to reduce the dependency on imported goods.

\section{Reference}

[1].Alemayehu, G., and T. Kibrom. 2008. The galloping inflation in Ethiopia: A cautionary tale for aspiring 'developmental states' in Africa. IAES Working Paper No. WP-A01-2011.

[2].Assefa, A. 2013. The political economy of food prices: The case of Ethiopia. WIDER Working Paper 2013/001, United Nations University.

[3]. Ahmed, H. A. (2007). Determinants of Inflation in Ethiopia: Ethiopian Development Research Institute. Addis Ababa.

[4]. Durevall, D., Loening, J. A. and Birro Y. A. (2010). Inflation Dynamics and Food Prices in Ethiopia Scandinavian Working Papers in Economics (S-WoPEc), No 478.

[5]. Emrta, A. (2013). Inflation and Economic Growth: An Estimate of the Threshold Level of Inflation for Ethiopia. Addis Ababa, Ethiopia: Ethiopian Economic Association (EEA).

[6]. http://www.trading economics.com

[7]. Kazi, M. A. and Munshi, M. A. (2012). Determinants of inflation in Bangladesh: An Empirical Investigation, Journal of Economics and Sustainable Development Vol.3 (12)

[8]. Khathlan, A. (2011). Inflation in the United Kingdom of Saudi Arabia: The bound test analyses. African Journal of Business Management, 5(24), 10156-10162

.[9]. Kibrom, T. (2008). The sources of the recent inflationary experience in Ethiopia, Mater of science thesis, department of economics, AAU, Addis Ababa, Ethiopia.

[10]. Laryea, S. A. and Sumaila, U. R. (2001). Determinants of Inflation in Tanzania. Chr. Michelsen Institute Development Studies and Human Rights, WP-12, $1-17$.

[11]. Mishkin, F. S. (2010). The economics of money, banking and financial markets. 9th ed. Addison-Wesley.

[12]. Mosayeb, P. and Mohammad, R. (2009). Sources of Inflation in Iran: An application of the real approach. International Journal of Applied Econometrics and Quantitative Studies, 6(1), $61-76$.

[13]. Olatunji, G. B. Omotesho, O. A., Ayinde, O. E. and Ayindo, K. (2010). Determinants of Inflation in Nigeria: A Co-integration approach. Paper presented at the Joint 3rd African association of agricultural economists, 1 -12 .

[14]. Ratnasiri, H. (2006). "The Main Determinants of Inflation in Sri Lanka: A VAR based Analysis", Central Bank of Sri Lanka, Staff Studies - Volume 39 N0 1 \& 2.

[15]. Robert, E. H. (1982). Inflation: causes and effects. United States of America: The National Bureau of Economic Research

[16]. Shahadudheen, I. (2012). A cointegration and Error Correction Approach to the Determinants of Inflation in India. International Journal of Economic Research, Vol 3(1): 105-112.

[17]. Sisay, M. (2008). Determinants of Recent Inflation inEthiopia. Munich Personal RePEc Archive. 